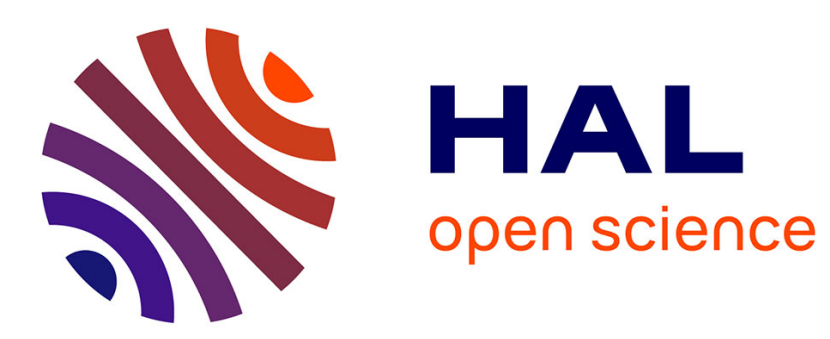

\title{
Conformational Study of the Jet-Cooled Diketopiperazine Peptide Cyclo Tyrosyl-Prolyl
} Ariel Pérez-Mellor, Ivan Alata, Valéria Lepère, Anne Zehnacker

\section{To cite this version:}

Ariel Pérez-Mellor, Ivan Alata, Valéria Lepère, Anne Zehnacker. Conformational Study of the JetCooled Diketopiperazine Peptide Cyclo Tyrosyl-Prolyl. Journal of Physical Chemistry B, 2019, 123 (28), pp.6023-6033. 10.1021/acs.jpcb.9b04529 . hal-02347969

\section{HAL Id: hal-02347969 https://hal.science/hal-02347969}

Submitted on 7 Nov 2020

HAL is a multi-disciplinary open access archive for the deposit and dissemination of scientific research documents, whether they are published or not. The documents may come from teaching and research institutions in France or abroad, or from public or private research centers.
L'archive ouverte pluridisciplinaire HAL, est destinée au dépôt et à la diffusion de documents scientifiques de niveau recherche, publiés ou non, émanant des établissements d'enseignement et de recherche français ou étrangers, des laboratoires publics ou privés. 


\title{
Conformational Study of the Jet-cooled Diketopiperazine Peptide cyclo Tyrosyl-Prolyl
}

\author{
Ariel Pérez-Mellor, Ivan Alata, Valeria Lepère, Anne Zehnacker * \\ Institut des Sciences Moléculaires d'Orsay (ISMO), CNRS, Univ. Paris-Sud, \\ Université Paris-Saclay, F-91405 Orsay, France \\ *e-mail anne.zehnacker-rentien@u-psud.fr
}

\begin{abstract}
The conformational landscape of the diketopiperazine (DKP) dipeptide built on tyrosine and proline, namely, cyclo Tyr-Pro, is studied by combining resonance-enhanced multiphoton ionisation, double resonance IR-UV spectroscopy, and quantum chemical calculations. Despite the geometrical constraints due the two aliphatic rings, DKP and proline, cyclo Tyr-Pro is a flexible molecule. For both diastereoisomers, cyclo LTyr-LPro and cylo LTyr-DTyr, two structural families coexist under supersonic jet conditions. In the most stable conformation, the aromatic tyrosine substituent is folded over the DKP ring $\left(\mathrm{g}^{+}\right.$geometry of the aromatic ring) as it is in the solid state. The other structure is completely extended ( $\mathrm{g}^{-}$geometry of the aromatic ring) and resembles that proposed for the vapor phase. IR-UV results are not sufficient for unambiguous assignment of the observed spectra to either folded or extended conformations and the simulation of the vibronic pattern of the $S_{0}-S_{1}$ transition is necessary. Still, the comparison between IR-UV results and anharmonic calculations allow explaining the minor structural differences between cyclo LTyr-LPro and cylo LTyr-DPro in terms of different $\mathrm{NH} . . . \pi$ and $\mathrm{CH} . . \pi$ interactions.
\end{abstract}




\section{Introduction}

Diketopiperazine (DKP) dipeptides are cyclic dipeptides, built from the intramolecular peptide bond formation, and are naturally present in natural environments. For example, that built on phenylalanine (Phe), cyclo Phe-Phe, is a decomposition product of the commonly used sweetener Aspartame. Other DKP dipeptides are present in plants or fungi. In particular cyclo tyrosyl-proline (cyclo Tyr-Pro), commonly known as Maculosin, is a natural phytotoxin ${ }^{1}$. Several DKP dipeptides, due to their stability and resistance to proteolysis, have been tested for anti-cancerous or antibiotic properties. ${ }^{2}$

From a structural point of view, these dipeptides do not possess a terminal charged group, in contrast to linear peptides or $\alpha$-amino acids. Thus, their crystal structure does not involve strong electrostatic interaction between ionic heads, as it is the case for example for solid alanine, ${ }^{3}$ but often rests on hydrogen-bonded networks involving the amide $\mathrm{NH}$ and $\mathrm{CO}$, similar to those observed in $\beta$-sheet structures of proteins. ${ }^{4}$ However, protic side chains on the residues can also participate in the hydrogen-bonded network, as found in polymorphs of cyclo Glu-Glu. ${ }^{5}$ The rigid DKP ring has limited conformational mobility and is usually non-planar because of the steric hindrance brought upon by the substituents. It ranges from pseudo boat or chair to intermediate twisted shapes. ${ }^{6-7}$ The residue side chains have more conformational freedom. Equilibrium between different conformations often happens in solution, which involves different orientations of the side chain. Residues with a bulky aromatic substituent such as Phe, Tyr or Trp, tend to adopt a flagpole position of the substituent ${ }^{8-9}{ }^{10}$, that is folded over the DKP ring.

We have recently characterized spectroscopically the structure of DKP dipeptides built on two identical aromatic amino acids like Phe or Tyr, both neutral or protonated in the gas phase or in the solid phase. ${ }^{11-14}$ The idea behind this work is to assess the structural differences between dipeptides having the two residues with the same absolute configuration, i.e. the natural $\mathrm{L}$ configuration, or with different, L and D, absolute configurations. Our study concluded that, unless specific interactions are present, the most stable structure is a "folded-extended" geometry, with one of the aromatic ring folded over the DKP ring and the other one extended. Cyclo LTyr-LTyr stands out by the presence of an additional conformer in which the two aromatic rings are held parallel to each other thanks to an $\mathrm{OH}$... O hydrogen bond formed between the two hydroxyls. This geometry is only possible for cyclo LTyr-LTyr and not for cyclo LTyr-DTyr. Studies under supersonic jet conditions indicate that electronic excitation is 
localized on one ring only, for both cyclo Phe-Phe and cyclo Tyr-Tyr, as is the charge in the radical cation. Here, we extend our studies to jet-cooled cyclo Tyr-Pro, shown in Figure 1. This system has only one bulky aromatic substituent. Moreover, proline stands out among the $\alpha-$ amino acids by its $\mathrm{N}$-alkylamide bond when incorporated into a peptide. This results in additional conformational bias induced by the proline cycle fused with the DKP ring. This might modify the competition between optimizing the interaction between the aromatic side chain and the DKP and minimization of steric hindrance, which has been proposed for explaining the geometry of aromatic-containing DKP dipeptides. ${ }^{15}$

Several structural studies have been already devoted to cyclo Tyr-Pro in the condensed phase. X-ray crystallography concludes that two close conformers of cyclo LTyr-LPro crystallize in the space group $\mathrm{P} 2{ }_{1} 2{ }_{1} 2$, with the tyrosyl side chains folded on the DKP ring in a flattened chair conformation. $^{7}$ No data are available for the enantiopure cyclo LTyr-DPro. However, in the racemic mixture, the tyrosine side chain is also folded on the DKP ring, which adopts a twistboat conformation with pseudo $\mathrm{C}_{2 \mathrm{v}}$ symmetry. ${ }^{16}$

A folded structure similar to that observed in the solid is proposed to explain the electronic circular dichroism (ECD) spectrum of cyclo LTyr-LPro in solution. ${ }^{17-18}$ This structure is not modified when changing the solvent or the absolute configuration of the residues. The geometry proposed to account for the photo-electron spectrum of cyclo LTyr-LPro in the vapor phase is at odds with the findings in solution and consist of an extended conformer involving a weak NH... $\pi$ interaction. ${ }^{19}$

In this work, we combine conformer-selective vibrational spectroscopy of jet-cooled cyclo LTyr-LPro and cyclo LTyr-DPro, referred to as c-LL and c-LD hereafter, with quantum chemical calculations, to shed light on their gas-phase structure. The size of the system is small enough for full anharmonic calculations, which allows the subtle spectroscopic differences between the two diastereomers to be reproduced theoretically.

\section{Theoretical and experimental methods}

\section{II-1. Nomenclature of the Studied Systems}

The numbering of the atoms and the angular parameters describing the molecular geometry are shown in Figure 1. The dipeptides geometry is described by the conformation of the DKP ring itself, that of the proline ring, and the orientation of the aromatic substituent relative to the amide bond. ${ }^{20}$ For the aromatic substituent orientation, Young et al, reported three geometries 
as minima of the potential energy surface. ${ }^{21}$ They are defined by a Newman projection along the $\mathrm{C}_{5} \mathrm{C}_{1}$ bond: two gauche geometries, $\mathrm{g}^{+}$and $\mathrm{g}^{-}$, correspond to dihedral angles $\tau\left(\mathrm{N} \mathrm{C}_{1} \mathrm{C}_{5} \mathrm{C}_{6}\right)$ of $\sim 60^{\circ}$ and $\sim-60^{\circ}$ for the $\mathrm{L}$ residue, as shown in Figure 2. The trans $\mathrm{t}$ geometry corresponds to $\tau \sim 180^{\circ}$. The additional parameter I and II describes the orientation of the tyrosine hydroxyl relative to the DKP ring, as indicated in Figure 2. The conformation of proline is determined in a similar manner, by $\tau^{\prime}\left(\mathrm{N} \mathrm{C}_{3} \mathrm{C}_{12} \mathrm{C}_{13}\right)$, defined by a Newman projection along the $\mathrm{C}_{14} \mathrm{C}_{3}$ bond. However, due to the constraints imposed by its cyclic nature, only the $\mathrm{g}^{-}$orientation exists.

The nomenclature used here starts with "c-" denoting the cyclic nature of the dipeptide, followed by the orientation of the tyrosine aromatic side chain $\mathrm{g}^{+}, \mathrm{g}^{-}$, or $\mathrm{t}$, followed by I or II for the tyrosyl $\mathrm{OH}$ position. The Tyr residue is always of natural absolute configuration $\mathrm{L}$. The second parameter $\mathrm{g}^{-}$represents the orientation of the proline, followed by the subscript $\mathrm{D}$ if proline is in the absolute configuration D. When non-specified otherwise, the absolute configuration is the natural $\mathrm{L}$ configuration.

\section{II-2. Theoretical Methods}

a) Exploration of the conformational landscape and geometry optimisation The potential energy surface (PES) was first explored using the OPLS-2005 force field combined with the advanced conformational search implemented in the MacroModel program of the Schrödinger package. ${ }^{22}$ Then, the obtained lowest-energy conformers were used as starting points for a relaxed scan along the dihedral angle $\tau$, by steps of ten degrees, which corresponds to an energy variation of less than $2 \mathrm{kcal} / \mathrm{mol}$. The resulting relaxed scan is presented in Figure S1 of the electronic supplementary information (ESI $\dagger$ ). All critical points (local minima or transition states) were fully optimized within the frame of the density functional theory (DFT) using the dispersion-corrected functional B3LYP-D3 ${ }^{23-24}$ associated with the Pople $6-311++\mathrm{g}(\mathrm{d}, \mathrm{p})$ split-valence basis set. $^{25}$ This level of theory satisfactorily reproduces the vibrational spectra of similar systems at an acceptable calculation cost. ${ }^{11,14,26}$ The systematic exploration of the PES by means of the relaxed scan does not yield new stable conformations relative to those obtained with the force field exploration.

b) Frequency calculations

The vibrational frequencies were first calculated within the frame of the harmonic approximation at the same level of theory. The absence of imaginary frequency was checked for all local minima found. Full anharmonic calculations were also performed by using the variational perturbation theory. ${ }^{27-29}$ The harmonic frequencies need to be scaled to account for 
anharmonicity and basis set incompleteness. ${ }^{30}$ To this end, we used the anharmonic frequencies to define the scaling factor as the range-specific slope of the linear regression between harmonic and anharmonic frequencies, for all the computed structures, as shown in Figure S2 of the ESI $\dagger$. The scaling factor for the fingerprint, the $v(\mathrm{CH})$, and the $v(\mathrm{NH}) / v(\mathrm{OH})$ region is $0.977,0.957$, 0.952, respectively. The idea behind this approach is to define a set of transferable scaling factors that can be used for similar or larger systems, such as dimers, which we are currently studying. Indeed, mode-dependent scaling factors based on an extensive library of systems improve agreement with the experiment. ${ }^{31-32}$ As mentioned below in the discussion, both anharmonic and scaled harmonic frequencies reproduce the experiment. Thus, we will limit the discussion on the neutral species to the anharmonic frequencies. For the cations, we use the harmonic frequencies scaled as described above. The spectra were simulated by convoluting the calculated frequencies by a Lorentzian shape (FWHM $8 \mathrm{~cm}^{-1}$ ) for better comparison with the experiment.

c) Electronic excited state and ionic state

The electronic excited state $S_{1}$ geometry was optimized at the time-dependent DFT (TD-DFT) level, using the same functional and basis set as $\mathrm{S}_{0}$. The radical cation was optimized at the same level of theory as the neutral by removing an electron from the calculated neutral forms, which reflects the vertical ionization process. The charge distribution was obtained from the Natural Bond Orbital (NBO) analysis. ${ }^{33}$ The vibrationally-resolved electronic transition was simulated based on the Franck-Condon principle. ${ }^{34-35}$ All calculations were performed with the Gaussian 09 package. ${ }^{36}$

\section{II-3. Experimental Methods}

The experimental set-up combines a supersonic expansion (General Valve) of Argon seeded with the dipeptide put into the gas phase by a homemade laser desorption source, and coupled with a $1 \mathrm{~m}$ time-of-flight mass spectrometer (Jordan) equipped with MCP detector, as detailed previously. ${ }^{37-38}$

Mass-resolved $\mathrm{S}_{0}-\mathrm{S}_{1}$ spectra were obtained by one-color resonance-enhanced two-photon ionization (RE2PI) spectroscopy, using a frequency-doubled dye laser (Sirah) pumped by the second harmonic of a YAG laser (Spectra). Vibrational spectra were obtained using the IR-UV double resonance technique, in the $v(\mathrm{NH})$ and $v(\mathrm{OH})$ stretch region. ${ }^{39-40}$ Fixing the UV probe on the main vibronic bands of the electronic spectrum and scanning the IR pump in the $3 \mu \mathrm{m}$ 
region allowed for the measurement of mass-resolved conformer-selective vibrational absorption spectra, as depletion of the UV probe-induced ion current.

The IR source was provided by an OPO/OPA system (Laser Vision) and was triggered $80 \mathrm{~ns}$ before the UV laser pulse for recording the IR spectrum of the electronic ground state and 50 ns after for recording IR absorption of the ion. A homemade active baseline subtraction scheme was used for monitoring the IR absorption as the difference in ion signal produced by successive UV laser pulses (one without and one with the IR laser). The resolution of the UV laser was $\sim 0.2 \mathrm{~cm}^{-1}$ and that of the IR OPO was $2 \mathrm{~cm}^{-1}$.

The peptides were purchased from Novopep Limited (Shanghai - China) and used without further purification.

\section{Results and Discussion}

\section{III-1. Theoretical Results}

The calculated minimum-energy conformers only differ by the orientation $\mathrm{g}^{+}, \mathrm{g}^{-}$, or $\mathrm{t}$ of the aromatic ring and the orientation, I or II, of the hydroxyl. As mentioned earlier, the proline has $\mathrm{g}^{-}$geometry in all the calculated conformers, whatever the absolute configuration. Six stable conformers are therefore expected for each stereoisomer. However, the results for the I and II conformers parallel each other, and the Gibbs energy difference between them is less than 0.2 $\mathrm{kcal} / \mathrm{mol}$, which is within the error. Therefore, we will limit the discussion to the II conformers, shown in Figure 3. Their relative Gibbs energies are listed in Table 1, as well as the angle $\tau$ describing the substituent orientation. We must keep in mind however that both I and II forms are expected to be trapped in our experimental conditions, as it is the case for tyrosine itself or for cyclo Tyr-Tyr. ${ }^{12,}{ }^{41}$ The energetic and structural parameters for the conformers with I orientation of the hydroxyl are given in Table S1 of the ESI†. Table S1 also lists the values of all the angles describing the geometry of the two aliphatic rings, the proline and the DKP.

c-LL: The most stable orientation of the aromatic ring is folded over the DKP ring and corresponds to a c- $\mathrm{g}_{I I}^{+} \mathrm{g}^{-}$conformer. The extended $\mathrm{c}-\mathrm{g}_{I I}^{-} \mathrm{g}^{-}$conformer is higher in energy by $0.5 \mathrm{kcal} / \mathrm{mol}$ and is therefore expected to be populated too. Lastly, the extended $\mathrm{c}-\mathrm{t}_{I I} \mathrm{~g}^{-}$ conformer is much higher in energy $(\sim 2 \mathrm{kcal} / \mathrm{mol})$ and is not expected to be populated in our experimental conditions.

As already mentioned for cyclo Phe-Phe and cyclo Tyr-Tyr, the most stable c- $\mathrm{g}_{I I}^{+} \mathrm{g}^{-}$conformer has a compact geometry, with the phenol folded over the DKP ring. This allows a $\mathrm{C}_{14} \mathrm{H} \ldots \pi$ 
interaction to take place from the $\mathrm{C}_{\beta} \mathrm{H}$ of proline. The geometry of the DKP ring is quasi-planar and the distance between $\mathrm{C}_{14} \mathrm{H}$ and the center of the phenol ring is $2.67 \AA$.

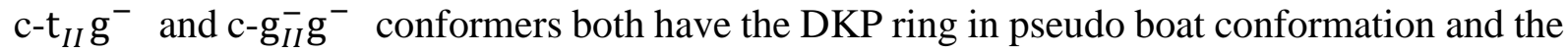
aromatic ring extended outwards. In $\mathrm{c}_{-} \mathrm{g}_{I I}^{-} \mathrm{g}^{-}$, the tyrosine residue is directed towards the tyrosine $\mathrm{NH}$, resulting to a weak $\mathrm{NH} . . . \pi$ interaction with a distance from the $\mathrm{NH}$ to the center of the phenol ring of $3.30 \AA$. In $\mathrm{c}^{-} \mathrm{t}_{I I} \mathrm{~g}^{-}$, the tyrosine residue is extended towards the proline amide CO.

c-LD: The results for c-LD parallel those described for c-LL except that all conformers have boat DKP geometry. Again, $\mathrm{c}^{-} \mathrm{g}_{I I}^{+} \mathrm{g}_{\mathrm{D}}^{-}$is the most stable geometry and only differs from its c-LL counterpart by the nature of the $\mathrm{CH}$... $\pi$ interaction, as already observed in cyclo Phe-Phe and cyclo Tyr-Tyr. It consists indeed in a $\mathrm{C}_{\alpha} \mathrm{H} \ldots \pi$ interaction in $\mathrm{c}^{-} \mathrm{g}_{I I}^{+} \mathrm{g}_{\mathrm{D}}^{-}$. Due to this interaction, the distance between $\mathrm{C}_{3} \mathrm{H}$ and the center of the phenol ring is short $(2.58 \AA)$. The second stable conformer, $\mathrm{c}-\mathrm{g}_{I I}^{-} \mathrm{g}_{D}^{-}$, involves an $\mathrm{NH} . . . \pi$ interaction with a distance between $\mathrm{NH}$ and the center of the phenol ring of $3.50 \AA$, slightly larger than in c-LL. Last, c- $\mathrm{t}_{I I} \mathrm{~g}_{D}^{-}$is completely extended and does not involve noticeable non-covalent interactions; the distance between $\mathrm{C}_{2} \mathrm{O}$ and the center of the ring is $3.88 \AA$. It should be noted that the energy gap between the most stable c$\mathrm{g}_{I I}^{+} \mathrm{g}_{\mathrm{D}}^{-}$conformer and $\mathrm{c}-\mathrm{g}_{I I}^{-} \mathrm{g}_{D}^{-}$or $\mathrm{c}-\mathrm{t}_{I I} \mathrm{~g}_{D}^{-}$is much larger in c-LD than c-LL and amounts to 1.4 and $3.7 \mathrm{kcal} / \mathrm{mol}$, respectively.

It should be noted that the most stable c-LD conformer is $2.06 \mathrm{kcal} / \mathrm{mol}$ lower in energy than the most stable c-LL conformer. This contrasts to the previous findings on neutral or protonated cyclo PhePhe, or neutral cyclo Ty-Tyr, in which homochirality was always favored. ${ }^{11-12,} 14$ Among the studied DKP dipeptides, cyclo Tyr-Pro stands out by the cyclic nature of the proline residues, which introduces additional conformational bias. As a result, the NH... $\pi$ interaction, which is stronger in cyclo LPhe-DPhe or cyclo LTyr-DTyr than in their c-LL counterpart, is weaker in c-LL for cyclo Tyr-Pro. However, c-LL and c-LD show a different geometry of the DKP ring, which counterbalances the effects of NH... $\pi$ interactions. While the DKP ring is almost planar in c-LL, it adopts in c-LD a boat conformation that allows optimizing the $\mathrm{CH} \ldots \pi$ interaction. The stronger $\mathrm{CH} \ldots \pi$ interaction in $\mathrm{c}-\mathrm{LD}$ manifests itself by a much shorter $\mathrm{CH} \ldots \pi$ distance $(2.58 \AA$ in c-LD vs. $2.67 \AA$ in c-LL). 


\section{III-2. Experimental Results}

\section{III-2 a. Electronic Spectroscopy}

The one-color REMPI electronic spectra of c-LL and c-LD are obtained by monitoring the mass of the parent ion at $m / z 260$ and are shown in Figure 4. Well-resolved sharp vibronic bands appear in the region of the first $\pi \pi^{*}$ electronic transition of tyrosine, which indicates that the molecules are efficiently cooled down. The lower-energy transition appears at different frequencies for the two diastereomers, $35498 \mathrm{~cm}^{-1}$ for c-LL vs. $35641 \mathrm{~cm}^{-1}$ for c-LD. These values are close to those for tyrosine, which range from $35491 \mathrm{~cm}^{-1}$ to $35650 \mathrm{~cm}^{-1}$ depending on the conformer ${ }^{41-45}$ or to those for cyclo Tyr-Tyr. ${ }^{12}$ Several vibronic bands appear in these spectra, suggesting strong vibronic activity and/or coexistence of conformers. The spectrum of c-LL shows four origin-like transitions noted A $\left(35498 \mathrm{~cm}^{-1}\right), \mathrm{B}\left(35532 \mathrm{~cm}^{-1}\right), \mathrm{C}\left(35592 \mathrm{~cm}^{-1}\right)$, $\mathrm{D}\left(35673 \mathrm{~cm}^{-1}\right)$ in Figure 4 . The four of them are followed by a three-membered progression built on a $29 \mathrm{~cm}^{-1}$ mode, as indicated in figure 4 . Bands also appear at $\mathrm{A}+68 \mathrm{~cm}^{-1}$ and $\mathrm{B}+65$ $\mathrm{cm}^{-1}$, while $\mathrm{D}$ is characterized by the presence of a doublet split by $4 \mathrm{~cm}^{-1}$ for each member of the $29 \mathrm{~cm}^{-1}$ progression. The vibronic pattern of c-LD is much simpler than that of c-LL. It mostly comprises two three-membered progressions built on a $\sim 35 \mathrm{~cm}^{-1}$ mode, starting at 35710 $\mathrm{cm}^{-1}$ and $35752 \mathrm{~cm}^{-1}$ (band C and D in Figure 4, respectively), accompanied by two weaker bands, A $\left(35641 \mathrm{~cm}^{-1}\right)$, and $\mathrm{B}\left(35656 \mathrm{~cm}^{-1}\right)$, which also behave like transition origins.

\section{III-2 b. Vibrational Spectroscopy in the electronic ground state and assignment}

Figures 5 and Figure 6 show conformer-specific vibrational spectra obtained in the region of the $v(\mathrm{NH})$ and $v(\mathrm{OH})$ stretches by setting the probe on the electronic transitions labelled $\mathrm{A}$ and $\mathrm{C}$ for c-LL and A and D for c-LD (see the electronic spectrum in Figure 4). The other vibrational spectra are shown in Figures S3 and S4 of the ESI $\dagger$. All the spectra display identical phenol $v(\mathrm{OH})$ stretch frequency $\left(3650 \mathrm{~cm}^{-1}\right)$, very close to that of tyrosine $\left(3660 \mathrm{~cm}^{-1}\right) .^{41}$

c-LL shows an identical position of the $v(\mathrm{NH})$ stretching frequency, within the experimental error, for all the bands probed. However, the spectra display different behaviors in terms of relative intensity $v(\mathrm{NH}) / v(\mathrm{OH})$, which allow classifying them in two categories. Category I (bands A and B) is characterized by similar intensities for the $v(\mathrm{OH})$ and $v(\mathrm{NH})$ stretching modes, while $v(\mathrm{OH})$ is twice as intense as $v(\mathrm{NH})$ in category II (bands $\mathrm{C}, \mathrm{D}$ and $\mathrm{E}$ ). This suggests two families of conformers. 
In contrast to c-LL, the $v(\mathrm{NH})$ stretches appear at different frequencies in c-LD, namely, 3429 $\mathrm{cm}^{-1}$ when probing bands $\mathrm{C}$ or $\mathrm{D}$ and $3418 \mathrm{~cm}^{-1}$ when probing band $\mathrm{A}$ and $\mathrm{B}$. Again, this result suggests two families of conformers for c-LD. A shoulder appears at the low-energy side of the $v(\mathrm{NH})$ stretch of $\mathrm{C}$ and $\mathrm{D}$, possibly due to the presence of an overtone or combination band, as already observed for other DKP dipeptides. ${ }^{12,14}$ The most apparent difference between the two diastereomers is that the $v(\mathrm{NH})$ stretch is shifted up in energy by $\sim 30 \mathrm{~cm}^{-1}$ in c-LD relative to c-LL.

The harmonic and anharmonic $v(\mathrm{NH})$ and $v(\mathrm{OH})$ stretch frequencies are listed in Table 2 . The calculated $v(\mathrm{OH})$ stretch frequency is identical for all the conformers of c-LL $\left(\sim 3650 \mathrm{~cm}^{-1}\right)$ like in the experimental spectrum and does not help for the attribution. A tentative assignment can rest only on the $v(\mathrm{NH})$ stretch region and on thermodynamic considerations. We must also keep in mind that the I and II rotamers, which only differ by the $\mathrm{OH}$ orientation, have exactly the same calculated IR spectrum and energy and should appear as pairs in the REMPI spectrum. The two most stable c- $\mathrm{g}_{I I}^{+} \mathrm{g}^{-} / \mathrm{c}^{-} \mathrm{g}_{I}^{+} \mathrm{g}^{-}$and $\mathrm{c}-\mathrm{g}_{I I}^{-} \mathrm{g}^{-} / \mathrm{c}^{-} \mathrm{g}_{I}^{-} \mathrm{g}^{-}$conformers have their $\mathrm{v}(\mathrm{NH})$ at 3400 $\mathrm{cm}^{-1}$, which compares well with the experimental value of $3398 \mathrm{~cm}^{-1}$, and are therefore good

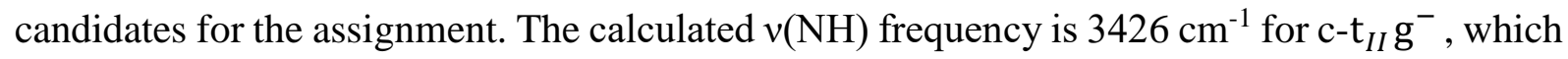
allows discarding this higher-energy structure. The assignment to either $\mathrm{c}^{-} \mathrm{g}_{I I}^{+} \mathrm{g}^{-} / \mathrm{c}_{-} \mathrm{g}_{I}^{+} \mathrm{g}^{-}$or $\mathrm{c}-\mathrm{g}_{I I}^{-} \mathrm{g}^{-} / \mathrm{c}-\mathrm{g}_{I}^{-} \mathrm{g}^{-}$conformers rests on the relative intensity of the $v(\mathrm{NH})$ and $v(\mathrm{OH})$ stretches. For the most stable folded $\mathrm{c}-\mathrm{g}_{I I}^{+} \mathrm{g}^{-}$conformer, the calculated intensity of $\mathrm{v}(\mathrm{OH})$ is larger than that of $v(\mathrm{NH})$, as observed for C, D and E. The calculated spectrum of the slightly less stable extended $\mathrm{c}-\mathrm{g}_{I I}^{-} \mathrm{g}^{-}$conformer shows similar intensities for $v(\mathrm{OH})$ and $v(\mathrm{NH})$, as observed for A and $\mathrm{B}$. It is therefore tempting to assign bands $\mathrm{A}$ and $\mathrm{B}$ to $\mathrm{c}-\mathrm{g}_{I I}^{-} \mathrm{g}^{-}$and $\mathrm{c}-\mathrm{g}_{I}^{-} \mathrm{g}^{-}$and bands $\mathrm{C}$ and $\mathrm{D}$ to $\mathrm{c}-\mathrm{g}_{I I}^{+} \mathrm{g}^{-}$and $\mathrm{c}_{-} \mathrm{g}_{I}^{+} \mathrm{g}^{-}$. Similar reasoning can be followed for the c-LD diastereomer. Although the intense combination band calculated for $c-g_{I I}^{-} g_{D}^{-}$is hardly observed in the experimental spectrum of $\mathrm{C}$ or $\mathrm{D}$, we tend to assign the $\mathrm{C}$ and $\mathrm{D}$ bands to the $\mathrm{c}-\mathrm{g}_{I I}^{-} \mathrm{g}_{D}^{-}$and c$\mathrm{g}_{I}^{-} \mathrm{g}_{D}^{-}$conformers family. This assignment rests on the comparison between the calculated and experimental $v(\mathrm{NH})$ stretch frequencies and thermodynamics considerations, which allow us excluding the $\mathrm{c}_{-\mathrm{II}}^{-} \mathrm{g}_{D}^{-}$conformer. At this stage, it is not possible to make a definite assignment. As we shall discuss later on the basis of FFC calvulations, we assign the most intense bands to the $\mathrm{c}-\mathrm{g}_{I I}^{-} \mathrm{g}_{D}^{-}$and $\mathrm{c}-\mathrm{g}_{I}^{-} \mathrm{g}_{D}^{-}$conformers. The weaker A and B bands may be assigned to the $\mathrm{c}-\mathrm{g}_{I I}^{+} \mathrm{g}_{D}^{-}$ and $\mathrm{c}-\mathrm{g}_{I}^{+} \mathrm{g}_{D}^{-}$conformers.

Anharmonic calculations show that the $v(\mathrm{CO})$ overtone is very close to the $v(\mathrm{NH})$ stretch and is slightly active. It might gain intensity through Fermi resonance with the $v(\mathrm{NH})$ stretch and 
be responsible for the observed shoulder. Lastly, the blue shift of the $v(\mathrm{NH})$ stretch in c-LD compared to c-LL is well reproduced by the calculations.

\section{III-2 c. Vibrational Spectroscopy of the radical cation}

The vibrational spectrum of the radical cation is obtained as a photo-dissociation action spectrum by monitoring the intensity of the fragment ion at $m / z 154$ (see Figure 7). It shows a single band readily assigned to the $v(\mathrm{OH})$ stretch at $3563 \mathrm{~cm}^{-1}$ and $3567 \mathrm{~cm}^{-1}$ for c-LL and c-LD, respectively. The $v(\mathrm{OH})$ stretch frequency is shifted down in energy by about $85 \mathrm{~cm}^{-1}$ compared to the neutral ground state, a value slightly smaller than that observed in phenol $\left(124 \mathrm{~cm}^{-1}\right),{ }^{46-}$

${ }^{47}$ but close to that measured in the radical cation of cyclo Tyr-Tyr $\left(3572 \mathrm{~cm}^{-1}\right) .{ }^{12}$ Identical $\mathrm{m} / \mathrm{z}$ 154 fragment is observed for both diastereomers. It corresponds to the cleavage of $C_{1} C_{5}\left(C_{\alpha} C_{\beta}\right.$ of Tyr) bond accompanied by proton transfer from the Tyr part to the peptide ring. It indicates charge migration from the initially ionized phenol to the peptide ring. This transfer must happen after IR absorption because the measured $v(\mathrm{OH})$ stretch frequency is characteristic of a phenol radical cation.

The cation is optimized after removing an electron from the three stable $\mathrm{c}-\mathrm{g}_{I I}^{+} \mathrm{g}^{-},{\mathrm{c}-\mathrm{g}_{I I}^{-}}^{-}$, and $\mathrm{c}-\mathrm{t}_{I I} \mathrm{~g}^{-}$conformers. For $\mathrm{c}-\mathrm{g}_{I I}^{+} \mathrm{g}^{-}$and $\mathrm{c}-\mathrm{g}_{I I}^{-} \mathrm{g}^{-}$, the geometry is hardly modified relative to the neutral ground state. The only modification is a small change in the $\tau$ angle, from 66 to $69^{\circ}$ and -60 to $-69^{\circ}$ for $\mathrm{c}-\mathrm{g}_{I I}^{+} \mathrm{g}^{-}$and $\mathrm{c}-\mathrm{g}_{I I}^{-} \mathrm{g}^{-}$, respectively. In contrast, that of $\mathrm{c}-\mathrm{t}_{I I} \mathrm{~g}^{-}$changes more, from -153 to $-171^{\circ}$. This change in $\tau$ corresponds to a rotation of the aromatic ring and in turn optimization of the interaction between $\mathrm{CO}$ and the aromatic ring. Indeed, this interaction, which was repulsive in the neutral, is attractive in the ion due to the positive charge on the aromatic ring. This interaction results to additional stabilization of $\mathrm{c}^{-} \mathrm{t}_{I I} \mathrm{~g}^{-}$, which is the most

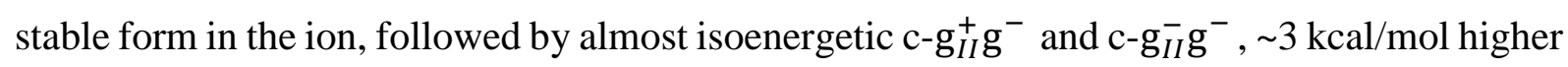
in energy (see Table S2 of the ESI $\dagger$ ). The $v(\mathrm{OH})$ stretch frequency is $3574 \mathrm{~cm}^{-1}$ for $\mathrm{c}^{-} \mathrm{g}_{I I}^{+} \mathrm{g}^{-}$and $3589 \mathrm{~cm}^{-1}$ for $\mathrm{c}-\mathrm{g}_{I I}^{-} \mathrm{g}^{-}$or $\mathrm{c}-\mathrm{t}_{I I} \mathrm{~g}^{-}$. Although $\mathrm{c}-\mathrm{g}_{I I}^{+} \mathrm{g}^{-}$is higher in energy than $\mathrm{c}^{-\mathrm{t}_{I I}} \mathrm{~g}^{-}$, its $\mathrm{v}(\mathrm{OH})$ stretch frequency corresponds better to the measured value $\left(3567 \mathrm{~cm}^{-1}\right)$.

The same trends are observed for c-LD. c- $\mathrm{t}_{I I} \mathrm{~g}_{D}^{-}$is the most stable form, c- $\mathrm{g}_{I I}^{+} \mathrm{g}_{D}^{-}$and c- $\mathrm{g}_{I I}^{-} \mathrm{g}_{D}^{-}$ being higher in energy by 5.4 and $6.4 \mathrm{kcal} / \mathrm{mol}$. As observed in the neutral, the energy gap between the most stable conformer and the others is larger in c-LD than c-LL. The calculated $v(\mathrm{NH})$ and $v(\mathrm{OH})$ stretch frequencies are listed in Table S2 of the ESI $\uparrow$. All the conformers have their $v(\mathrm{OH})$ stretch frequency at $3585 \pm 1 \mathrm{~cm}^{-1}$, close to the experimental value of 3563 $\mathrm{cm}^{-1}$. Still, the agreement between calculated and experimental $v(\mathrm{OH})$ stretch frequencies is not 
as good as in the electronic ground state, probably because ionization vertical excitation reaches a high-energy region of the PES, with at least $1 \mathrm{eV}$ excess energy after the calculations. In all the calculated structures, the charge is mostly localized on the phenol ring. For example, the NBO charge on the phenol is 0.74 in $\mathrm{c}^{-\mathrm{g}_{I I}^{+} \mathrm{g}^{-}}$. It is of the same order as observed in cyclo Tyr-Tyr (0.63), except that in cyclo Tyr-Tyr the charge is borne by the extended aromatic ring.

\section{III-2 d. Simulation of The $S_{0}-S_{1}$ spectrum}

The first electronic transition, $\mathrm{S}_{0} \rightarrow \mathrm{S}_{1}$, has $\pi \pi^{*}$ character, as indicated by the electron density difference between $S_{0}$ and $S_{1}$ drawn in Figure 8. The transition mostly involves HOMO $\rightarrow$ LUMO excitation ( $70 \%$ ), accompanied by minor contributions (less than $20 \%$ ) of HOMO$3 \rightarrow \mathrm{LUMO}+1$ or HOMO-3 $\rightarrow$ LUMO+2 excitations, as shown in Figure S5 and S6 of the ESI $\uparrow$. The calculated $\mathrm{S}_{0} \rightarrow \mathrm{S}_{1}$ transition energies and intensities are listed in Table 3. Figure 9 shows the comparison between the experimental electronic spectrum and that simulated from Franck Condon factor calculations. In contrast to the previously studied cyclo Phe-Phe, the inclusion of the Herzberg-Teller term is not necessary, because the electronic transition is dipole allowed. The calculated origins are overestimated for all conformers; they are therefore shifted to match the experiment.

The lower-energy experimental origin observed for c-LL (A band at $35498 \mathrm{~cm}^{-1}$ ) is assigned to ${\mathrm{c}-\mathrm{g}_{I I}^{-}}^{-} \mathrm{g}^{-}$, which has the lowest calculated origin. All the calculated transitions are therefore shifted by $1204 \mathrm{~cm}^{-1}$ so that the $\mathrm{g}_{I I}^{-} \mathrm{g}^{-}$origin is superimposed with the $\mathrm{A}$ band. The vibronic pattern starting from bands A and B are satisfactorily reproduced by the spectrum calculated for ${\mathrm{c}-\mathrm{g}_{I I}^{-}}^{-} \mathrm{g}^{-}$and $\mathrm{c}^{-} \mathrm{g}_{I}^{-} \mathrm{g}^{-}$, respectively. Moreover, the progressions starting from bands $\mathrm{A}$ and $\mathrm{B}$, which correspond to an aromatic ring torsion at $34 \mathrm{~cm}^{-1}$ and the proline torsion at $64 \mathrm{~cm}^{-1}$, have comparable shapes and intensities, as expected for a pair of conformers that only differ by the orientation of the phenol hydroxyl. They indicate a moderate change in geometry upon electronic excitation. In particular, the puckering modes of DKP and proline are not active. It is interesting to note that the results obtained here (lowest energy transition for the $\mathrm{g}^{-}$ conformation of Tyr) parallel those of Shimozono et al. They reported the lower-energy transition for the so-called "B" conformer of Tyr, in which the phenyl is oriented towards the amino group. ${ }^{41}$

In contrast, $c-g_{I}^{+} g^{-}$shows extensive geometry change between $S_{1}$ and $S_{0}$, mainly due to a rotation of the phenol ring. For this reason, the FC calculations failed and only the stick bar showing the origin transition is indicated in Figure 9. Band $\mathrm{E}$ is assigned to a vibronic transition 
of the same conformer, as it does not appear in any of the other calculated spectra. Band $\mathrm{C}$ is tentatively assigned to $\mathrm{c}^{-} \mathrm{g}_{I}^{+} \mathrm{g}^{-}$based on its origin. It should be noted that bands $\mathrm{C}$ is followed by several weak bands, which could be due to the activity of low-frequency modes. The $S_{1}$ geometry of $\mathrm{c}_{-} \mathrm{g}_{I I}^{+} \mathrm{g}^{-}$is slightly different from that in $\mathrm{S}_{0}$. The bands starting from $\mathrm{D}$ and above can be tentatively assigned to this conformer based on its calculated origin and vibrational pattern. Lastly, $\mathrm{c}-\mathrm{t}_{I I} \mathrm{~g}^{-}$has the highest transition origin with a marked change in geometry between $S_{1}$ and $S_{0}$. This observation parallels the results of Shimozono et al., which indicate the highest energy transition for the so-called II conformer of Tyr, in which the phenyl is oriented towards the carboxyl group. ${ }^{41}$ The very weak bands at $\sim 350-400 \mathrm{~cm}^{-1}$ above the A origin could be assigned to $c-\mathrm{t}_{I I} \mathrm{~g}^{-}$. However, based on thermodynamics, it is more likely that these bands are due to weak vibronic bands of more stable conformers.

The spectrum of c-LD is simpler. The calculated origin of ${\mathrm{c}-\mathrm{g}_{I I}^{-}}^{-} \mathrm{g}_{D}^{-}$is shifted by $1062 \mathrm{~cm}^{-1}$ to reproduce the $\mathrm{C}$ band at $35710 \mathrm{~cm}^{-1}$. The bands $\mathrm{C}$ at $35710 \mathrm{~cm}^{-1}$ and $\mathrm{D}$ at $35752 \mathrm{~cm}^{-1}$ are then assigned to the origin of $\mathrm{c}-\mathrm{g}_{I}^{-} \mathrm{g}_{D}^{-}$and $\mathrm{c}-\mathrm{g}_{I I}^{-} \mathrm{g}_{D}^{-}$, respectively. The geometry of $\mathrm{c}-\mathrm{g}_{I I}^{-} \mathrm{g}_{D}^{-}$does not change much upon electronic excitation, except the orientation of the phenol ring around $\mathrm{C}_{5} \mathrm{C}_{1}$. This torsion is responsible for the short vibrational progression calculated at $27 \mathrm{~cm}^{-1}$. The origin transitions of $\mathrm{c}-\mathrm{g}_{I}^{+} \mathrm{g}_{D}^{-}$and $\mathrm{c}-\mathrm{g}_{I I}^{+} \mathrm{g}_{D}^{-}$are red-shifted compared to $\mathrm{c}-\mathrm{g}_{I}^{-} \mathrm{g}_{D}^{-}$and very close to each other. Due to the abrupt change in geometry between $S_{0}$ and $S_{1}$, only the origin transition can be computed. These results suggest that bands $\mathrm{A}$ at $35641 \mathrm{~cm}^{-1}$ and $\mathrm{B}$ at $35656 \mathrm{~cm}^{-1}$ are the origin transitions of $\mathrm{c}-\mathrm{g}_{I}^{+} \mathrm{g}_{D}^{-}$and $\mathrm{c}-\mathrm{g}_{I I}^{+} \mathrm{g}_{D}^{-}$, respectively. Surprisingly, the bands assigned to $\mathrm{c}-\mathrm{g}_{I}^{+} \mathrm{g}_{D}^{-}$and $\mathrm{c}-\mathrm{g}_{I I}^{+} \mathrm{g}_{D}^{-}$are very weak in the electronic spectrum, although these structures are calculated to be the most stable. This can be due to fast conformer-specific non-radiative processes. However, due to the closeness of the IR and UV spectra of $\mathrm{c}-\mathrm{g}_{I}^{+} \mathrm{g}_{D}^{-}$and $\mathrm{c}-\mathrm{g}_{I I}^{+} \mathrm{g}_{D}^{-}$, and $\mathrm{c}-\mathrm{g}_{I}^{-} \mathrm{g}_{D}^{-}$and $\mathrm{c}-\mathrm{g}_{I I}^{-} \mathrm{g}_{D}^{-}$, the assignment is only tentative.

\section{Conclusion}

The two diastereomers of cyclo Tyr-Pro were studied under supersonic expansion conditions. Despite the presence of two sterically constrained rings, the DKP and the proline, this system shows conformational flexibility. In particular, all the structures appear as pairs related to the phenol hydroxyl isomerism. Two main families are observed experimentally, involving either $\mathrm{g}^{+}$or $\mathrm{g}^{-}$orientation of the aromatic substituent, with proline always in a $\mathrm{g}^{+}$orientation. The $\mathrm{c}-$ $\mathrm{g}^{+} \mathrm{g}^{-}$conformations in which the phenol ring is folded over the DKP ring are the most stable. The observed structure is the same as detected in the solid. ${ }^{48}$ The $\mathrm{g}^{+}$orientation is identical to 
that observed for the folded aromatic ring in the most stable form of the bichromophoric dipeptides cyclo Ty-Tyr or cyclo Phe-Phe. ${ }^{11-12,14}$ The $\mathrm{c}-\mathrm{g}_{I I}^{+} \mathrm{g}^{-} / \mathrm{c}-\mathrm{g}_{I}^{+} \mathrm{g}^{-}$in c-LL are stabilized by a $\mathrm{C}_{\beta} \mathrm{H} \ldots \pi$ interaction involving the $\mathrm{C}_{\beta} \mathrm{H}$ of proline. Due to the sterical constraints induced by the proline ring, the interaction is not very strong and the distance between $\mathrm{C}_{\beta} \mathrm{H}$ and the center of the ring is large $(2.68 \AA)$. These conformers are characterized by extensive change in geometry upon electronic excitation, as expected from the interaction between the aromatic chromophore and the rest of the molecule.

In c-LD, similar structures c- $\mathrm{g}_{I I}^{+} \mathrm{g}_{D}^{-} / \mathrm{c}-\mathrm{g}_{I}^{+} \mathrm{g}_{D}^{-}$are observed and are the most stable too. They differ from their c-LL counterpart by the nature and the strength of the stabilizing $\mathrm{CH}$... $\pi$ interaction, which involves $\mathrm{C}_{\alpha} \mathrm{H} \ldots \pi$ in c-LD. The CH... $\pi$ interaction is much stronger in c-LD than in c$\mathrm{LL}(\mathrm{CH} \ldots \pi$ distance $\sim 2.57 \AA$ ) , because it is favored by the boat conformation of the DKP ring. This may explain that, in contrast with previously studied DKP dipeptide, c-LD is more stable than c-LL. ${ }^{11-12,14}$ In contrast to $\mathrm{c}-\mathrm{LL}$, the $\mathrm{c}-\mathrm{g}_{I I}^{+} \mathrm{g}_{D}^{-} / \mathrm{c}-\mathrm{g}_{I}^{+} \mathrm{g}_{D}^{-}$pair appears very weakly in the REMPI spectrum, despite its stability, due to the lower oscillator strength of the transition and possibly non-radiative processes.

The second observed family, $\mathrm{c}^{-\mathrm{g}^{-}} \mathrm{g}^{-}$, is an extended conformation in which the phenol slightly interacts with the $\mathrm{NH}$ group of the tyrosine amino acid. The $\mathrm{g}^{-}$orientation is identical to that observed for the extended aromatic ring in the most stable form of the bichromophoric dipeptides cyclo Ty-Tyr or cyclo Phe-Phe. ${ }^{11-12,14}$ These conformers are observed in both c-LL and c-LD and their electronic spectrum is characterized by vibrational progressions built on the aromatic ring and proline torsions.

Lastly, the c-t $\mathrm{g}^{-}$conformation is too high in energy to be populated in our experimental conditions. In this structure, there is limited interaction between tyrosine and the rest of the molecule. However, it becomes the most stable in the radical cation.

An important finding of this work is that the IR spectroscopy alone would give ambiguous conclusions concerning the assignment. The preliminary assignment resting on IR spectroscopy can be confirmed only by simulating the electronic spectra. Simulation of Franck-Condon progressions has already proven to be very powerful for elucidating structures, for example for isolated protonated species either in jet-cooled conditions or in a cryogenic ion trap. ${ }^{49-50}$ Indeed, the structural differences between the two diastereomers are not very large and mainly consist in the nature of the $\mathrm{CH} \ldots \pi$ interaction in the $\mathrm{c}^{-} \mathrm{g}^{+} \mathrm{g}^{-}$folded conformers and in the strength of the $\mathrm{NH} . . . \pi$ interaction in the extended $\mathrm{c}^{-\mathrm{g}^{-}} \mathrm{g}^{-}$conformers. However, the electronic spectra 
strongly differ from each other. Studied on protonated cyclo Tyr-Pro and its dimer are currently in progress.

\section{Supporting Information}

Energetic and geometrical parameters of the most stable structures of cyclo Tyr-Pro, as well as the transition states separating them. Scaled harmonic frequencies of the $v(\mathrm{NH})$ and $v(\mathrm{OH})$ stretching modes of the radical cation of c-LL and c-LD. Infrared spectra of c-LL and c-LD in the region of the $v(\mathrm{NH})$ and $v(\mathrm{OH})$ stretching modes.

\section{Acknowledgments}

The research described here has been supported by the ANR contract (ESBODYR ANR-14CE06-0019-03). This work is supported by a public grant from the "Laboratoire d'Excellence Physics Atom Light Mater" (LabEx PALM) overseen by the French National Research Agency (ANR) as part of the "Investissements d'Avenir" program (reference: ANR-10-LABX-0039). We acknowledge the use of the computing center MésoLUM of the LUMAT research federation (FR LUMAT 2764).

\section{References}

1. Stierle, A. C.; Cardellina, J. H.; Strobel, G. A. Maculosin, A Host-Specific Phytotoxin for Spotted Knapweed from Alternaria-Alternata. Proc. Natl. Acad. Sci. U. S. A. 1988, 85 (21), 8008-8011.

2. Milne, P. J.; Hunt, A. L.; Rostoll, K.; Van Der Walt, J. J.; Graz, C. J. The biological activity of selected cyclic dipeptides. J. Pharm. Pharmacol. 1998, 50 (12), 1331-7.

3. Lehmann, M. S.; Koetzle, T. F.; Hamilton, W. C. Precision Neutron-Diffraction Structure Determination of Protein and Nucleic-Acid Components .1. Crystal and Molecular Structure of AminoAcid L-Alanine. J. Am. Chem. Soc. 1972, 94 (8), 2657-\&.

4. Corey, R. B. The Crystal Structure of Diketopiperazine. J. Am. Chem. Soc. 1938, 60, 1598-1604.

5. Mendham, A. P.; Palmer, R. A.; Potter, B. S.; Dines, T. J.; Snowden, M. J.; Withnall, R.; Chowdhry, B. Z. Vibrational spectroscopy and crystal structure analysis of two polymorphs of the diamino acid peptide cyclo(L-Glu-L-Glu). J. Raman Spectrosc. 2010, 41 (3), 288-302.

6. Carlson, K. L.; Lowe, S. L.; Hoffmann, M. R.; Thomasson, K. A. Theoretical UV circular dichroism of aliphatic cyclic dipeptides. J. Phys. Chem. A 2005, 109 (24), 5463-5470.

7. Milne, P. J.; Oliver, D. W.; Roos, H. M. Cyclodipeptides - Structure and Conformation of Cyclo(Tyrosyl Prolyl). J. Crystallogr. Spectrosc. Res. 1992, 22 (6), 643-649.

8. Kopple, K. D.; Marr, D. H. Conformation of cyclic peptides. The folding of cyclic dipeptides containing an aromatic side chain. J. Am. Chem. Soc. 1967, 89 (24), 6193-200.

9. Lin, C.-F.; Webb, L. E. Crystal structures and conformations of the cyclic dipeptides cyclo(Glycyl-L-tyrosyl) and cyclo-(L-seryl-L-tyrosyl) Monohydrate. J. Am. Chem. Soc. 1973, 95 (20), 6803-11. 
10. Wiedemann, S.; Metsala, A.; Nolting, D.; Weinkauf, R. The dipeptide cyclic(glycyltryptophanyl) in the gas phase: A concerted action of density functional calculations, S-0-S-1 two-photon ionization, spectral UV/UV hole burning and laser photoelectron spectroscopy. Phys. Chem. Chem. Phys. 2004, 6 (10), 2641-2649.

11. Alata, I.; Perez-Mellor, A.; Ben Nasr, F.; Scuderi, D.; Steinmetz, V.; Gobert, F.; Jaidane, N. E.; Zehnacker-Rentien, A. Does the Residues Chirality Modify the Conformation of a Cyclo-Dipeptide? Vibrational Spectroscopy of Protonated Cyclo-diphenylalanine in the Gas Phase. J. Phys. Chem. A 2017, 121 (38), 7130-7138.

12. BenNasr, F.; Perez-Mellor, A.; Alata, I.; Lepere, V.; Jaidane, N.-E.; Zehnacker, A. Stereochemistry-dependent hydrogen bonds stabilise stacked conformations in jet-cooled cyclic dipeptides: (LD) vs. (LL) cyclo tyrosine-tyrosine. Faraday Discuss. 2018, 212, 399.

13. Perez-Mellor, A.; Zehnacker, A. Vibrational circular dichroism of a 2,5-diketopiperazine (DKP) peptide: Evidence for dimer formation in cyclo LL or LD diphenylalanine in the solid state. Chirality 2017, 29 (2), 89-96.

14. Perez-Mellor, A.; Alata, I.; Lepère, V.; Zehnacker, A. Chirality effects in the structures of jetcooled bichromophoric dipeptides. J. Mol. Spectrosc. 2018, in press.

15. Deslauriers, R.; Grzonka, Z.; Schaumburg, K.; Shiba, T.; Walter, R. C-13 NUCLEAR MAGNETICRESONANCE STUDIES OF CONFORMATIONS OF CYCLIC DIPEPTIDES. J. Am. Chem. Soc. 1975, 97 (18), 5093-5100.

16. Hong, Y. P.; Lee, S. H.; Choi, J. H.; Kashima, A.; Nakamura, G.; Suzuki, T. Crystal Structure and Spectroscopic Properties of Cyclic Dipeptide: A Racemic Mixture of cyclo(D-Prolyl-L-Tyrosyl) and cyclo(L-Prolyl-D-Tyrosyl). Bull. Korean Chem. Soc. 2014, 35 (8), 2299-2303.

17. Li, Z.; Mukamel, S. First-Principles Simulation of Amide and Aromatic Side Chain Ultraviolet Spectroscopy of a Cyclic Dipeptide. J. Phys. Chem. A 2007, 111 (45), 11579-11583.

18. Madison, V.; Young, P. E.; Blout, E. R. Cyclic peptides. 14. Conformational energy and circular dichroism of proline-containing cyclic dipeptides. J. Am. Chem. Soc. 1976, 98 (17), 5358-5364.

19. Arachchilage, A. P. W.; Wang, F.; Feyer, V.; Plekan, O.; Prince, K. C. Photoelectron spectra and structures of three cyclic dipeptides: PhePhe, TyrPro, and HisGly. J. Chem. Phys. 2012, 136 (12), 124301.

20. Budesinsky, M.; Cisarova, I.; Podlaha, J.; Borremans, F.; Martins, J. C.; Waroquier, M.; Pauwels, E. Structures of cyclic dipeptides: an X-ray and computational study of cis- and trans-cyclo(Pip-Phe), cyclo(Pro-Phe) and their N-methyl derivatives. Acta Crystallogr., Sect. B: Struct. Sci. 2010, 66, 662-677. 21. Young, P. E.; Madison, V.; Blout, E. R. Cyclic peptides. 15. Lanthanide-assisted carbon-13 and proton NMR analysis of preferred side-chain rotamers in proline-containing cyclic dipeptides. J. Am. Chem. Soc. 1976, 98 (17), 5365-5371.

22. MacroModel version 9.8; ed. Schrödinger, LLC: New York, NY, 2010. MacroModel version 9.8; ed. Schrödinger, LLC: New York, NY, 20102010.

23. Grimme, S.; Antony, J.; Ehrlich, S.; Krieg, H. A consistent and accurate ab initio parametrization of density functional dispersion correction (DFT-D) for the 94 elements H-Pu. J. Chem. Phys. 2010, 132 (15), 154104

24. Grimme, S.; Ehrlich, S.; Goerigk, L. Effect of the Damping Function in Dispersion Corrected Density Functional Theory. J. Comput. Chem. 2011, 32 (7), 1456-1465.

25. Frisch, M. J.; Pople, J. A.; Binkley, J. S. SELF-CONSISTENT MOLECULAR-ORBITAL METHODS .25. SUPPLEMENTARY FUNCTIONS FOR GAUSSIAN-BASIS SETS. J. Chem. Phys. 1984, 80 (7), 3265-3269.

26. Lepere, V.; Le Barbu-Debus, K.; Clavaguera, C.; Scuderi, D.; Piani, G.; Simon, A.-L.; Chirot, F.; MacAleese, L.; Dugourd, P.; Zehnacker, A. Chirality-dependent structuration of protonated or sodiated polyphenylalanines: IRMPD and ion mobility studies. Phys. Chem. Chem. Phys. 2016, 18 (3), 1807-17.

27. Bloino, J.; Barone, V. A second-order perturbation theory route to vibrational averages and transition properties of molecules: General formulation and application to infrared and vibrational circular dichroism spectroscopies. J. Chem. Phys. 2012, 136 (12), 124108. 
28. Bloino, J.; Baiardi, A.; Biczysko, M. Aiming at an accurate prediction of vibrational and electronic spectra for medium-to-large molecules: An overview. Int. J. Quantum Chem. 2016, 116 (21), $1543-1574$.

29. Bloino, J.; Biczysko, M.; Barone, V. Anharmonic Effects on Vibrational Spectra Intensities: Infrared, Raman, Vibrational Circular Dichroism, and Raman Optical Activity. J. Phys. Chem. A 2015, 119 (49), 11862-11874.

30. Johnson, R. D.; http://cccbdb.nist.gov/vibscalejust.asp. NIST Computational Chemistry Comparison and Benchmark Database. (accessed January 15th 2019).

31. Gloaguen, E.; Mons, M. Isolated Neutral Peptides. In Gas-Phase Ir Spectroscopy and Structure of Biological Molecules, Rijs, A. M.; Oomens, J., Eds. 2015; Vol. 364, pp 225-270.

32. Plowright, R. J.; Gloaguen, E.; Mons, M. Compact Folding of Isolated Four-Residue Neutral Peptide Chains: H-Bonding Patterns and Entropy Effects. ChemPhysChem 2011, 12 (10), 1889-1899.

33. Reed, A. E.; Curtiss, L. A.; Weinhold, F. Intermolecular interactions for a natural bond orbital, donor-acceptor viewpoint. Chem. Rev. 1988, 88 (6), 899-926.

34. Santoro, F.; Improta, R.; Lami, A.; Bloino, J.; Barone, V. Effective method to compute FranckCondon integrals for optical spectra of large molecules in solution. J. Chem. Phys. 2007, 126 (16), 169903

35. Santoro, F.; Improta, R.; Lami, A.; Bloino, J.; Barone, V. Effective method to compute FranckCondon integrals for optical spectra of large molecules in solution. J. Chem. Phys. 2007, 126 (8), 084509 .

36. Frisch, M. J.; Trucks, G. W.; Schlegel, H. B.; Scuseria, G. E.; Robb, M. A.; Cheeseman, J. R.; Scalmani, G.; Barone, V.; Mennucci, B.; Petersson, G. A., et al. Gaussian 09, Revision D.01, Gaussian Inc.: Wallingford CT, 2009.

37. Sen, A.; Bouchet, A.; Lepere, V.; Le Barbu-Debus, K.; Scuderi, D.; Piuzzi, F.; Zehnacker-Rentien, A. Conformational analysis of quinine and its pseudo enantiomer quinidine: a combined jet-cooled spectroscopy and vibrational circular dichroism study. J. Phys. Chem. A 2012, 116 (32), 8334-44.

38. Sen, A.; Lepere, V.; Le Barbu-Debus, K.; Zehnacker, A. How do Pseudoenantiomers Structurally Differ in the Gas Phase? An IR/UV Spectroscopy Study of Jet-Cooled Hydroquinine and Hydroquinidine. ChemPhysChem 2013, 14 (15), 3559-68.

39. Tanabe, S.; Ebata, T.; Fujii, M.; Mikami, N. OH Stretching Vibrations of Phenol-(H2O)n(n=1-3) Complexes Observed by Ir-Uv Double-Resonance Spectroscopy. Chem. Phys. Lett. 1993, 215 (4), 347352.

40. Pribble, R. N.; Zwier, T. S. Size-Specific Infrared-Spectra of Benzene- $\left(\mathrm{H}_{2} \mathrm{O}\right)_{(\mathrm{n})}$ Clusters $(\mathrm{n}=1$ through 7) - Evidence for Noncyclic $\left(\mathrm{H}_{2} \mathrm{O}\right)_{(\mathrm{n})}$ Structures. Science 1994, 265 (5168), 75-79.

41. Shimozono, Y.; Yamada, K.; Ishiuchi, S.-i.; Tsukiyama, K.; Fujii, M. Revised conformational assignments and conformational evolution of tyrosine by laser desorption supersonic jet laser spectroscopy. Phys. Chem. Chem. Phys. 2013, 15 (14), 5163-5175.

42. Martinez, S. J.; Alfano, J. C.; Levy, D. H. The Electronic Spectroscopy of the Amino-Acids Tyrosine and Phenylalanine in a Supersonic Jet. J. Mol. Spectrosc. 1992, 156 (2), 421-430.

43. Inokuchi, Y.; Kobayashi, Y.; Ito, T.; Ebata, T. Conformation of L-tyrosine studied by fluorescencedetected UV-UV and IR-UV double-resonance spectroscopy. J. Phys. Chem. A 2007, 111 (17), 32093215.

44. Grace, L. I.; Cohen, R.; Dunn, T. M.; Lubman, D. M.; de Vries, M. S. The R2PI spectroscopy of tyrosine: A vibronic analysis. J. Mol. Spectrosc. 2002, 215 (2), 204-219.

45. Abo-Riziq, A.; Grace, L.; Crews, B.; Callahan, M. P.; van Mourik, T.; de Vries, M. S. Conformational Structure of Tyrosine, Tyrosyl-glycine, and Tyrosyl-glycyl-glycine by Double Resonance Spectroscopy. J. Phys. Chem. A 2011, 115 (23), 6077-6087.

46. Fujii, A.; Sawamura, T.; Tanabe, S.; Ebata, T.; Mikami, N. Infrared dissociation spectroscopy of the $\mathrm{OH}$ stretching vibration of phenol-rare gas van der Waals cluster ions. Chem. Phys. Lett. 1994, 225 (1-3), 104-107. 
47. Fujii, A.; Iwasaki, A.; Mikami, N. Observation of intramolecular hydrogen bonds of ofluorophenol ions by using autoionization detected infrared spectroscopy. Chem. Lett. 1997, 26 (11), 1099-1100.

48. Grant, G. D.; Hunt, A. L.; Milne, P. J.; Roos, H. M.; Joubert, J. A. The structure and conformation of the tryptophanyl diketopiperazines cyclo(Trp-Trp)center dot $\mathrm{C} 2 \mathrm{H} 6 \mathrm{SO}$ and cyclo(Trp-Pro). J. Chem. Crystallogr. 1999, 29 (4), 435-447.

49. Alata, I.; Omidyan, R.; Dedonder-Lardeux, C.; Broquier, M.; Jouvet, C. Electronically excited states of protonated aromatic molecules: benzaldehyde. Phys. Chem. Chem. Phys. 2009, 11 (48), 11479-11486.

50. Feraud, G.; Broquier, M.; Dedonder-Lardeux, C.; Gregoire, G.; Soorkia, S.; Jouvet, C. Photofragmentation Spectroscopy of Cold Protonated Aromatic Amines in the Gas Phase. Phys. Chem. Chem. Phys. 2014, 16 (11), 5250-5259. 


\begin{tabular}{|c|c|c|c|c|c|c|c|}
\hline Conformer & $\begin{array}{c}\Delta \mathrm{E}(0 \mathrm{~K}) \\
(\mathrm{kcal} / \mathrm{mol})\end{array}$ & $\Delta G(\mathrm{kcal} / \mathrm{mol})$ & \multicolumn{3}{|c|}{ Interaction distance $(\AA)$} & DKP geometry & $\begin{array}{l}\text { Tyrosine } \\
\text { position }\end{array}$ \\
\hline $\mathrm{c}-\mathrm{g}_{I I}^{+} \mathrm{g}^{-}$ & 0,00 & 0,00 & 66 & 2,67 & $\mathrm{C}_{14} \mathrm{H} \ldots \pi$ & Quasi planar & \\
\hline $\mathrm{c}-\mathrm{g}_{I I}^{-} \mathrm{g}^{-}$ & 2,23 & 0,47 & -60 & 3,30 & NH... $\pi$ & Boat & Equatorial \\
\hline $\mathrm{c}-\mathrm{t}_{I I} \mathrm{~g}^{-}$ & 3,78 & 1,90 & -154 & 2,45 & $\mathrm{C}_{2} \mathrm{O} \ldots \mathrm{HC}_{11}$ & Boat & Equatorial \\
\hline $\mathrm{c}-\mathrm{g}_{I I}^{+} \mathrm{g}_{\mathrm{D}}^{-}$ & $0.00(-1.54)^{*}$ & $0.00(-2.06)^{*}$ & 63 & 2,58 & $\mathrm{C}_{3} \mathrm{H} \ldots \pi$ & Boat & Axial \\
\hline $\mathrm{c}-\mathrm{g}_{I I}^{-} \mathrm{g}_{\bar{D}}^{-}$ & 2,77 & 1,40 & -60 & 3,50 & NH... $\pi$ & Boat & Axial \\
\hline $\mathrm{c}-\mathrm{t}_{I I} \mathrm{~g}_{\bar{D}}^{-}$ & 5,32 & 3,72 & -175 & 3,88 & $\mathrm{C}_{2} \mathrm{O} \ldots \pi$ & Boat & Axial \\
\hline
\end{tabular}

Table 1: Relative electronic energy $\Delta E(0 K)$ and Gibbs free energy $\Delta G$. The value in parentheses (*) is the difference between the most stable c-LD conformer and the most stable c- LL. The dihedral angles $\tau\left(\mathrm{N} \mathrm{C}_{1} \mathrm{C}_{5} \mathrm{C}_{6}\right)$ defines the orientation of the aromatic ring. 


\begin{tabular}{|c|c|c|c|c|c|c|c|c|c|c|c|c|}
\hline \multirow{3}{*}{ Conformer } & \multicolumn{4}{|c|}{$\mathbf{v}(\mathrm{NH})$} & \multicolumn{4}{|c|}{$\mathrm{v}(\mathrm{OH})$} & \multirow{2}{*}{\multicolumn{2}{|c|}{$\begin{array}{c}2 \mathrm{v}(\mathrm{CO})_{1} \\
\text { Anharmonic }\end{array}$}} & \multirow{2}{*}{\multicolumn{2}{|c|}{$\begin{array}{c}2 \mathrm{v}(\mathrm{CO})_{2} \\
\text { Anharmonic }\end{array}$}} \\
\hline & \multirow{2}{*}{$\begin{array}{c}\text { Harmoni } \\
v^{*}\end{array}$} & \multirow[b]{2}{*}{ I } & \multicolumn{2}{|c|}{ Anharmonic } & \multicolumn{2}{|c|}{ Harmonic } & \multicolumn{2}{|c|}{ Anharmonic } & & & & \\
\hline & & & $v$ & I & $v^{*}$ & $\mathbf{I}$ & $v$ & $\mathbf{I}$ & $v$ & $\mathbf{I}$ & $v$ & I \\
\hline $\mathrm{c}-\mathrm{g}_{I I}^{+} \mathrm{g}^{-}$ & 3397 & 18 & 3400 & 12 & 3649 & 71 & 3650 & 59 & 3346 & 4 & 3417 & 3 \\
\hline $\mathrm{c}-\mathrm{g}_{I}^{+} \mathrm{g}^{-}$ & 3397 & 19 & & & 3650 & 67 & & & & & & \\
\hline $\mathrm{c}-\mathrm{g}_{I I}^{-} \mathrm{g}^{-}$ & 3404 & 80 & 3402 & 71 & 3651 & 77 & 3651 & 63 & 3377 & 4 & 3437 & 5 \\
\hline $\mathrm{c}-\mathrm{g}_{I}^{-} \mathrm{g}^{-}$ & 3404 & 81 & & & 3650 & 76 & & & & & & \\
\hline $\mathrm{c}-\mathrm{t}_{I I} \mathrm{~g}^{-}$ & 3424 & 28 & 3426 & 21 & 3651 & 71 & 3656 & 58 & 3382 & 4 & 3433 & 5 \\
\hline $\mathrm{c}-\mathrm{t}_{I} \mathrm{~g}^{-}$ & 3424 & 28 & & & 3652 & 71 & & & & & & \\
\hline $\mathrm{c}-\mathrm{g}_{I I}^{+} \mathrm{g}_{\bar{D}}^{-}$ & 3415 & 27 & 3422 & 6 & 3649 & 73 & 3651 & 60 & 3364 & 4 & 3416 & 4 \\
\hline $\mathrm{c}-\mathrm{g}_{I}^{+} \mathrm{g}_{\bar{D}}^{-}$ & 3416 & 27 & & & 3650 & 69 & & & & & & \\
\hline $\mathrm{c}-\mathrm{g}_{I I}^{-} \mathrm{g}_{\bar{D}}^{-}$ & 3414 & 29 & 3421 & 23 & 3651 & 79 & 3652 & 65 & 3374 & 4 & 3424 & 4 \\
\hline $\mathrm{c}-\mathrm{g}_{I}^{-} \mathrm{g}_{\bar{D}}^{-}$ & 3414 & 28 & & & 3650 & 75 & & & & & & \\
\hline $\mathrm{c}-\mathrm{t}_{I I} \mathrm{~g}_{\bar{D}}^{-}$ & 3421 & 29 & 3424 & 21 & 3652 & 71 & 3654 & 58 & 3389 & 4 & 3426 & 5 \\
\hline $\mathrm{c}-\mathrm{t}_{I} \mathrm{~g}_{\bar{D}}^{-}$ & 3421 & 29 & & & 3652 & 76 & & & & & & \\
\hline
\end{tabular}

Table 2 Calculated scaled harmonic $\left(v^{*}\right)$ and anharmonic $(v)$ frequencies $\left(\mathrm{cm}^{-1}\right)$ and intensities $(\mathrm{km} / \mathrm{mol})$ of the $v(\mathrm{NH})$ and $v(O H)$ stretching modes. The scaled factor for the harmonic frequencies is 0.952 


\begin{tabular}{|c|c|c|c|c|c|c|c|c|c|}
\hline \multirow{3}{*}{ Conformer } & \multicolumn{6}{|c|}{$\mathbf{S}_{\mathbf{0}} \rightarrow \mathbf{S}_{\mathbf{1}}$} & \multicolumn{3}{|c|}{$\mathbf{S}_{\mathbf{0}} \rightarrow \mathbf{D}_{\mathbf{0}}$} \\
\hline & \multirow{2}{*}{$\begin{array}{c}\text { VT } \\
(\mathrm{eV})\end{array}$} & \multirow{2}{*}{$\begin{array}{c}\text { TDMI }^{2} \\
\text { (a.u.) }\end{array}$} & \multirow{2}{*}{$\begin{array}{l}\text { AT } \\
(\mathrm{eV})\end{array}$} & \multicolumn{2}{|c|}{ OT } & \multirow{2}{*}{$\begin{array}{c}\text { RMSD } \\
(\AA) \\
\end{array}$} & \multirow{2}{*}{$\begin{array}{c}\text { VT } \\
(\mathrm{eV})\end{array}$} & \multirow{2}{*}{$\begin{array}{l}\text { AT } \\
(\mathrm{eV})\end{array}$} & \multirow{2}{*}{$\begin{array}{c}\text { RMSD } \\
\text { (̊) }\end{array}$} \\
\hline & & & & $(\mathrm{eV})$ & $\left(\mathrm{cm}^{-1}\right)$ & & & & \\
\hline $\mathrm{c}-\mathrm{g}_{I I}^{+} \mathrm{g}^{-}$ & 4,92 & 0,0186 & 4,75 & 4,58 & 36915 & 0,083 & 8,18 & 8,00 & 0,221 \\
\hline $\mathrm{c}-\mathrm{g}_{I I}^{-} \mathrm{g}^{-}$ & 4,88 & 0,0299 & 4,72 & 4,55 & 36702 & 0,088 & 8,07 & 7,95 & 0,088 \\
\hline $\mathrm{c}-\mathrm{t}_{I I} \mathrm{~g}^{-}$ & 4,92 & 0,0272 & 4,76 & 4,59 & 37046 & 0,134 & 7,92 & 7,56 & 0,853 \\
\hline c-g $\mathrm{g}_{I I}^{+} \mathrm{g}_{\mathrm{D}}^{-}$ & 4,89 & 0,0194 & 4,65 & 4,44 & 35825 & 0,475 & 8,10 & 7,97 & 0,092 \\
\hline $\mathrm{c}-\mathrm{g}_{I I}^{-} \mathrm{g}_{\bar{D}}^{-}$ & 4,89 & 0,0241 & 4,73 & 4,56 & 36787 & 0,154 & 8,10 & 7,88 & 0,219 \\
\hline $\mathrm{c}-\mathrm{t}_{I I} \mathrm{~g}_{D}^{-}$ & 4,88 & 0,0263 & 4,71 & 4,55 & 36666 & 0,311 & 7,89 & 7,62 & 0,449 \\
\hline
\end{tabular}

Table 3 Details of the $S_{0} \rightarrow S_{1}$ and $S_{0} \rightarrow D_{0}$ transitions. VT: Vertical transition. TDMI: Transition Dipole Moment Integral. AT: Adiabatic Transition. OT: Origin of the Transition calculated by correcting the AT by the difference in Zero-Point Energy (ZPE) between $S_{0}$ and $S_{1}$. RMSD: Root Mean Square Deviation between the geometry of ground state and the $S_{1}$ or $D_{0}$ geometry as appropriate. 
Figure Caption

Figure 1: Structure of cyclo Tyr-Pro and atom numbering. The angular parameters defining the geometry are as follows: $\phi_{1}\left(C_{2} N C_{3} C_{4}\right) \psi_{1}(N$ $\left.C_{3} C_{4} N\right) \omega_{1}\left(C_{3} C_{4} N C_{1}\right) \phi_{2}\left(C_{4} N C_{1} C_{2}\right) \psi_{2}\left(N C_{1} C_{2} N\right) \omega_{2}\left(C_{1} C_{2} N C_{3}\right) \boldsymbol{B}\left(N C_{12} C_{13} C_{14}\right) \boldsymbol{C}\left(C_{12} C_{13} C_{14} C_{3}\right) \boldsymbol{D}\left(C_{13} C_{14} C_{3} N\right) \boldsymbol{E}\left(C_{14} C_{3} N C_{12}\right)$

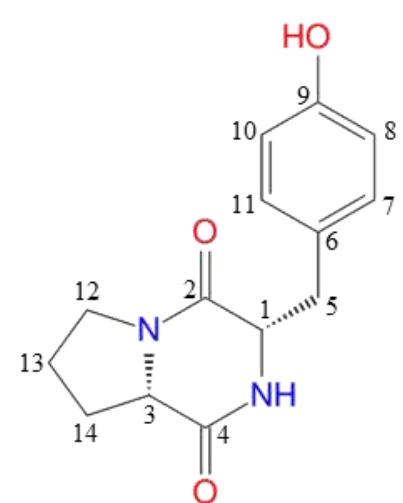

cyclo LTyr-LPro

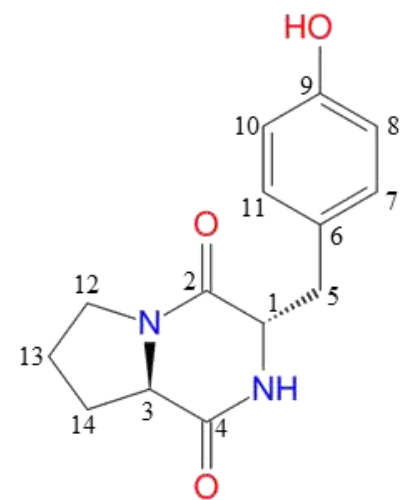

cyclo LTyr-DPro 
Figure 2: a) Newman projection along $C_{5} C_{1}$ for tyrosine and nomenclature for the aromatic substituent orientation in an L Tyr residue. In this scheme, the substituent is in $g^{+}$conformation. The two other orientations are indicated by the letters $t$ and $g^{-}$. Nomenclature for the hydroxyl orientation: anticlockwise (type I) orientation or clockwise orientation (type II). b) Newman projection along $C_{14} C_{3}$ for $D$ proline showing the $g^{-}$ conformation.

a)

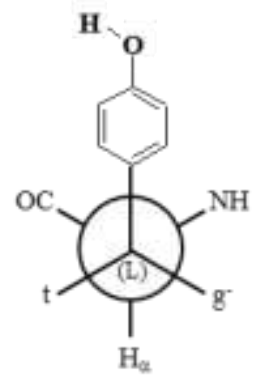

Type I

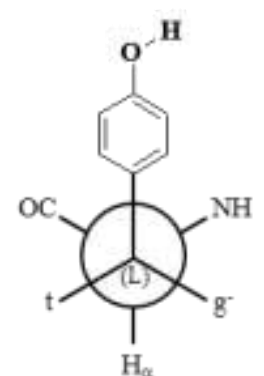

Type II b)



g position of D Pro 
Figure 3: Stable calculated structures of type II conformer of c-LL (left) and c-LD (right). The Gibbs energy $\Delta G$ is given in parentheses.

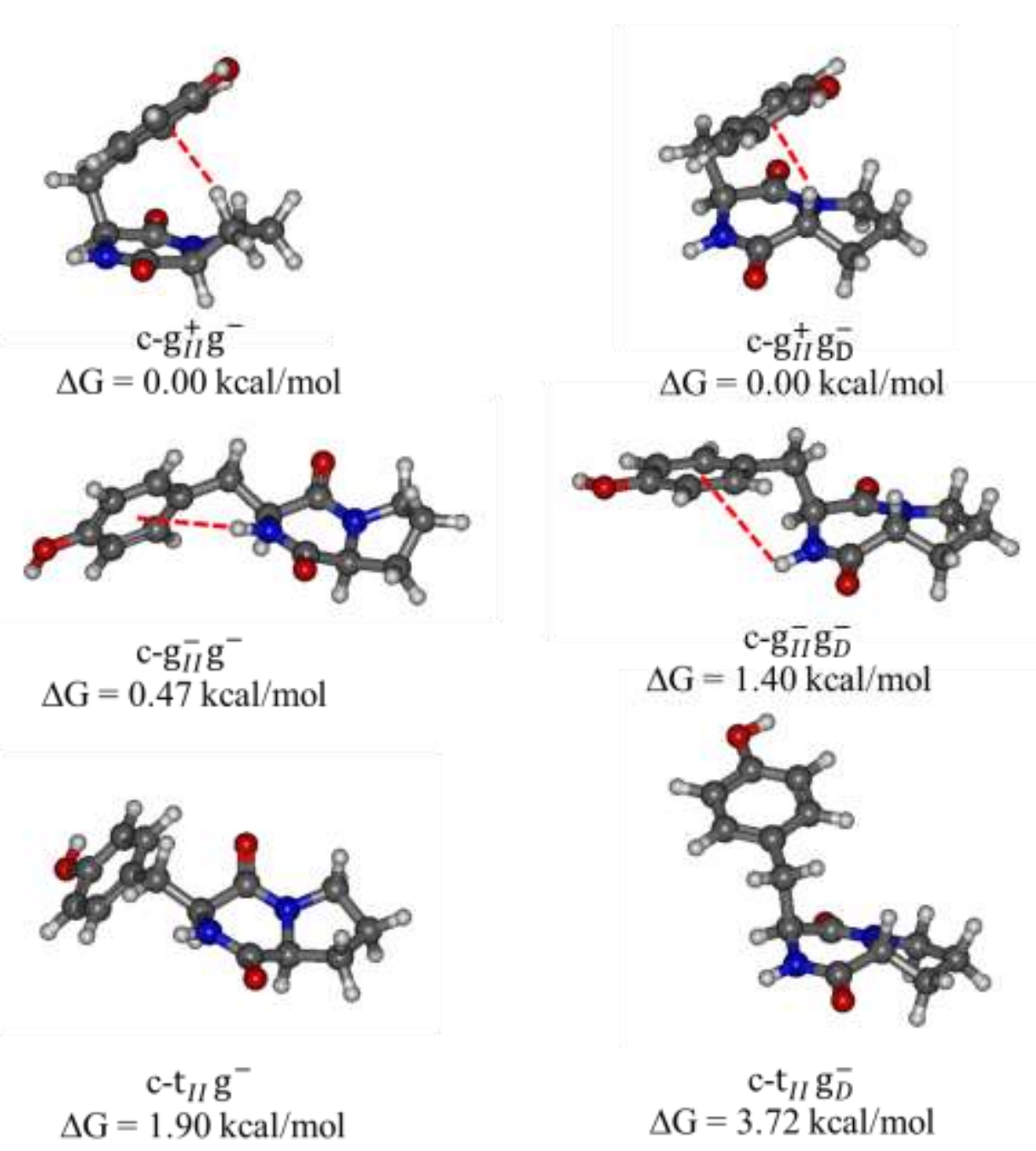


Figure 4: one-color REMPI spectra of jet-cooled cyclo Tyr-Pro in the region of the $S_{1}\left(\pi^{*}\right) \leftarrow$ $S_{0}\left(\pi^{*}\right)$ transition of tyrosine for $a$ ) $c$ - LL and $b$ ) $c$ - LD. The bands labelled with a letter are those probed for recording the ion-dip IR spectrum. The vertical scale is in arbitrary units.

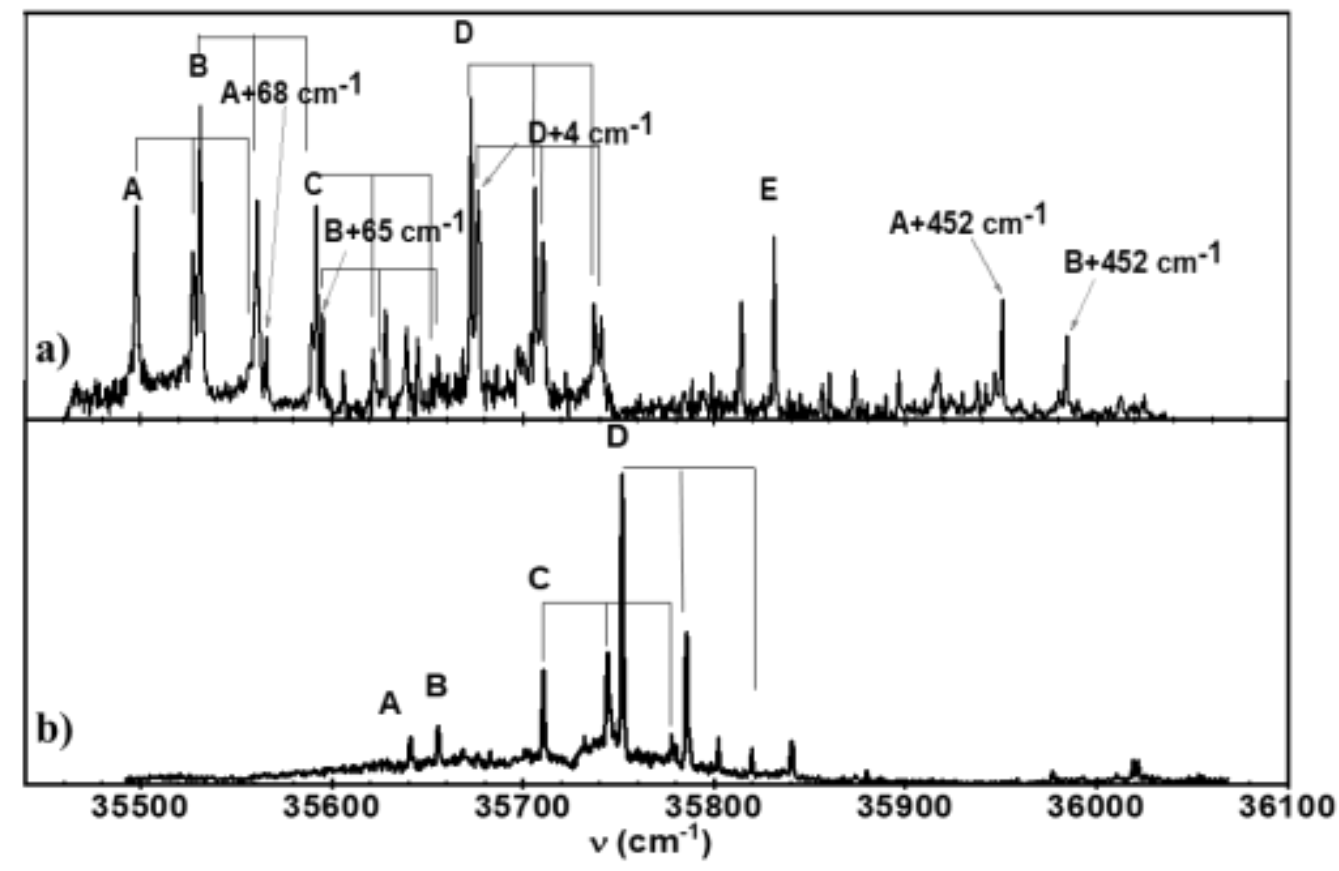


Figure 5: Infrared spectra of $c-L L$ in the region of the $\mathrm{v}(\mathrm{NH})$ and $\mathrm{v}(\mathrm{OH})$ stretching modes by probing $a$ ) band $A$ and $b$ ) band $C($ ), d) and e) simulated infrared spectra for the most stable TyrII-containing conformers. The stick bands are as follows: black-fundamentals bands, redovertones and green-combination bands.




Figure 6: Infrared spectra of $c-L D$ in the region of the $v(\mathrm{NH})$ and $v(\mathrm{OH})$ stretching modes by probing $a$ ) band $A$ and $b$ ) band $D(c), d$ ) and e) simulated infrared spectra for the most stable TyrII-containing conformers. The stick bands are as follows: black-fundamentals bands, redovertones and green-combination bands.

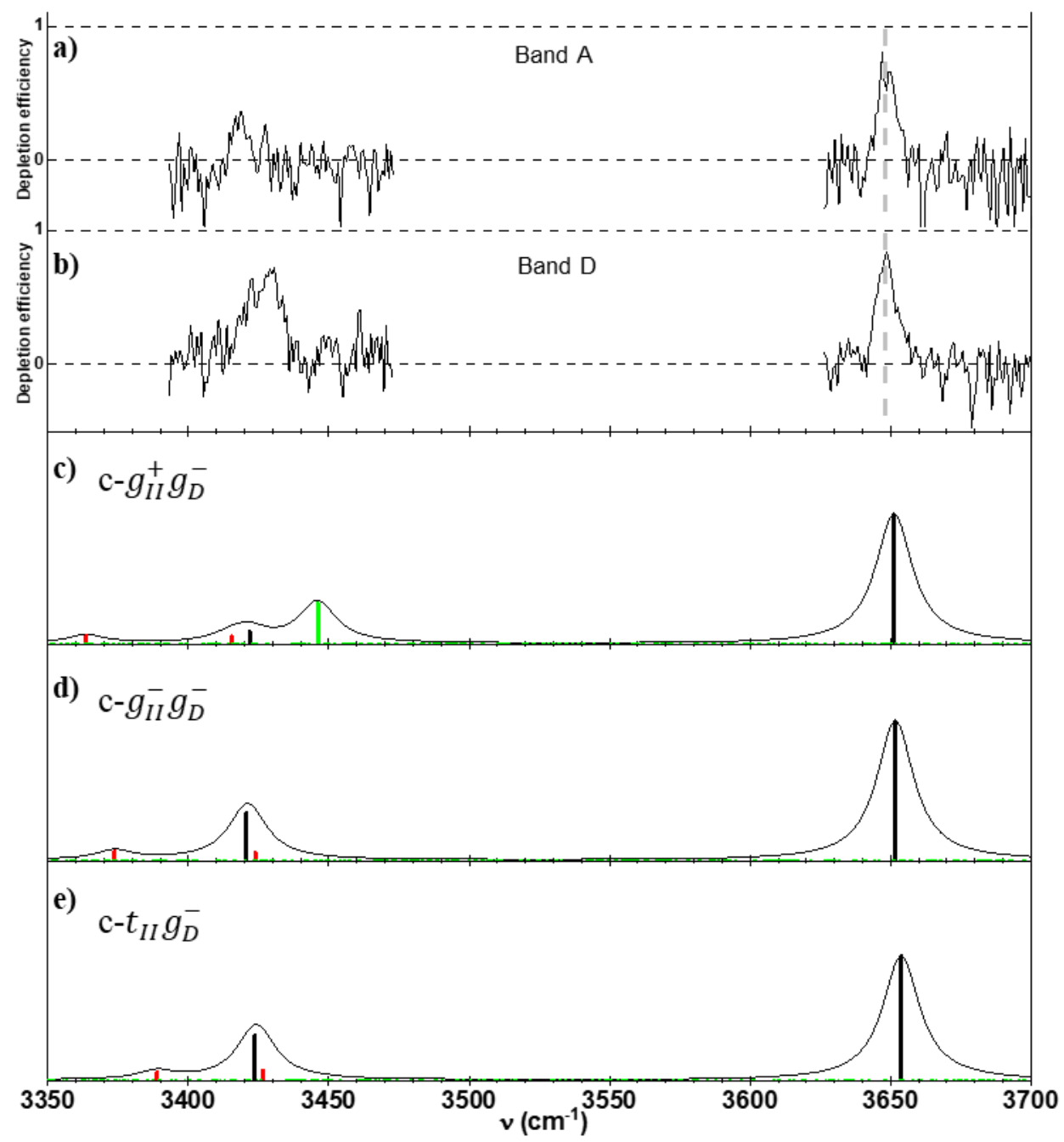


Figure 7: Infrared spectrum of the ion of a) $c-L L$ with the probe set on band $B$ and $b$ ) $c-L D$ with the probe set on band $D$, in the $v(\mathrm{OH})$ stretch region. The spectra are obtained by photodissociation action spectroscopy by monitoring the $\mathrm{m} / \mathrm{z} 154$ photo-fragment.

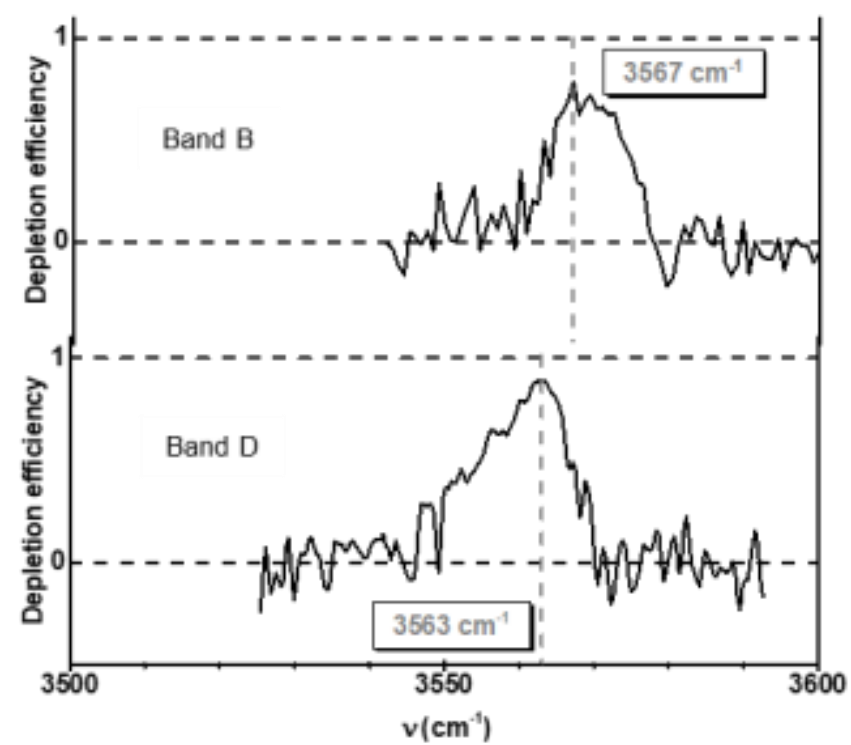


Figure 8: Electron density difference between $S_{1}$ and $S_{0}$. The electron density isovalue is set at 0.004 a.u. Positive-blue and negative-red are the signs of the electron density difference.


c- $g_{I I}^{+} g_{D}^{-}$

c- $g_{I I}^{-} g_{D}^{-}$

c- $t_{I I} g_{D}^{-}$ 
Figure 9: Comparison of the REMPI spectra with the simulated Franck-Condon overlap between $S_{0}$ and $S_{1}$ for each optimized conformer. The spectra are obtained by convoluting the electronic transition by a Lorentzian shape with an $F W H M=1.5 \mathrm{~cm}^{-1}$.

TOC Graphic



